http://doi.org/10.48195/sepe2021-037

\title{
USO DO ÓLEO DE LINHAÇA EM DIABETES MELLITUS TIPO II: UMA REVISÃO NARRATIVA ${ }^{1}$
}

\section{Natacha Fydryzewski Teixeira Domingues²; Elisângela Colpo³}

\section{RESUMO}

O presente estudo tem como objetivo revisar na literatura científica internacional sobre os benefícios do consumo de óleo de linhaça em pessoas com Diabetes Mellitus tipo II (DM II). Trata-se de uma revisão bibliográfica do tipo narrativa. Ao todo foram encontrados 16 artigos nas bases de dados PubMed, sendo selecionados três artigos após critérios de inclusão e exclusão. Foram correlacionados dados sociodemográficos, clínicos, homeostase da glicemia, perfil lipídico e biomarcadores de inflamação. O óleo de linhaça possui efeito benéfico para os portadores de DM II, auxiliando na secreção sérica da insulina, aumentando a expressão gênica de receptor ativado por proliferadores de peroxissoma gama, reduzindo os níveis de lipoproteína (a), IL-1, TNF- $\alpha$ e proteína $C$ reativa $(P C R)$. Outros estudos são necessários referente às recomendações de consumo e dosagem, visto que este é um questionamento a ser esclarecido para oferecer maior suporte no consumo do óleo de linhaça.

Palavras-chave: Alimentação, Oleaginosas; Doenças metabólicas; Marcadores inflamatórios; Nutrição;

Eixo Temático: Atenção Integral e Promoção à Saúde.

\footnotetext{
1 Trabalho apresentado a XXV Simpósio de Ensino, Pesquisa e Extensão - SEPE

Tema: Educação, saúde e tecnologia.

${ }^{2}$ Mestranda Enfermeira do Curso Ciência da Saúde e da Vida. Universidade Franciscana - UFN. E-mail: natacha nft@hotmail.com

3 Orientadora Prof. Dra. Elisângela Colpo. Universidade Franciscana - UFN. E-mail: elicolpo@ufn.edu.br
} 


\section{INTRODUÇÃO}

O Diabetes Mellitus tipo II (DM II), é definido como um distúrbio metabólico caracterizado por níveis elevados de glicose no sangue, sendo ocasionado pelo comprometimento da função secretora da célula $\beta$ e pela resistência à insulina que gera um aumento na produção hepática de glicose (SBD, 2020).

Para esclarecer a etiologia do DM II, estudos propõem que o meio ambiente e fatores genéticos são os principais fatores no período inicial da vida e na fase intrauterina. Indivíduos com baixo peso ao nascer apresentam níveis plasmáticos mais elevados de pró-insulina, indicativo de maior risco para 0 desenvolvimento futuro de DM II ou síndrome metabólica (BARKER et al., 1993; WEl et al., 2003).

Por ser considerada uma doença crônica, o seu tratamento implica motivar a pessoa a criar um plano terapêutico adequado e individualizado. 0 tratamento envolve uma série de variáveis passando por modificações na dieta, atividade física regular, autovigilância, autocuidado e adesão ao regime medicamentoso oral e/ou insulinoterapia que são essenciais para um bom controle glicêmico, prevenindo complicações futuras e consequentemente, trazendo uma melhor qualidade de vida (BARROS, 2008; IDF, 2017).

Em vista disso, o uso do óleo de semente de linhaça vem sendo vastamente utilizado auxilio no controle do diabetes. Esta semente oleaginosa é rica em ácido graxo poli-insaturado alfa-linolênico, mais conhecido como ômega3, o qual é considerado benéfico para doenças metabólicas crônicas (ALMEIDA et al., 2009; BASHO; BIN, 2010; ALVES et al., 2015).

O consumo dietético de fontes ricas em ômega-3 como salmão, sardinha, atum, sementes de chia, de linhaça, nozes entre outros, duas ou mais vezes por semana, ou ainda a suplementação deste nutriente pode apresentar redução de eventos cardiovasculares e mostram que podem levar à redução da resistência insulínica (FONSECA, GUTIERREZ, 1974; LOTTENBERG, 2008).)

Desta forma, o estudo teve como objetivo revisar na literatura científica 
internacional sobre os benefícios do consumo de óleo de linhaça em pessoas com diabetes mellitus tipo II (DM II).

\section{METODOLOGIA}

Trata-se de uma revisão bibliográfica, do tipo narrativa sobre a produção científica internacional para conhecer o que vem sendo abordado na literatura científica sobre os efeitos do consumo de óleo de linhaça em pessoas com diabetes mellitus tipo II. Artigos de revisão narrativa são publicações amplas utilizadas para descrever e refletir sobre determinado assunto, sob o ponto de vista teórico e contextual (ROTHER, 2007).

A busca foi realizada em suporte eletrônico, na base de dados Biblioteca Nacional de Medicina dos Estados Unidos (PubMed) a partir dos descritores encontrados no Portal DeCS (descritores em Ciências da Saúde): "Diabetes mellitus, type 2" and "Linseed Oil" and "Diet, Food, and Nutrition".

Para a condução deste estudo foram realizadas as seguintes etapas: a) estabelecimento da hipótese e objetivos da revisão narrativa; b) estabelecimento de critérios de inclusão e exclusão de artigos/trabalhos (para a realização da seleção da amostra); c) definição de informações a serem extraídas dos artigos/trabalhos selecionados; d) análise dos resultados; e) discussão e apresentação dos resultados.

A coleta foi realizada no período entre abril a junho de 2021, tendo como critérios de inclusão: trabalhos no formato de artigo em inglês, disponíveis na íntegra, on-line, que retratam a temática referente, publicados e indexados no banco de dados, dos últimos dez anos da publicação e pesquisa com seres humanos. Foram excluídos da pesquisa: livros, capítulos de livros, manuais, teses, capítulos de teses, dissertações, capítulos de dissertações, editoriais, resumos de trabalhos, trabalhos publicados em anais de eventos e trabalhos repetidos.

A seleção dos artigos foi realizada pela leitura dos títulos e dos resumos dos materiais encontrados. Para categorização do estudo, foi elaborada uma 
ficha de análise documental para levantamento dos dados dos artigos selecionados por meio da caracterização do estudo.

A autenticidade das ideias dos autores foi respeitada observando-se a Lei no 9.610 de 19 de fevereiro de 1998 (BRASIL, 1998), que regulamenta os direitos autorais no Brasil. Desse modo, a amostra final do estudo constituiu-se de quatro artigos, os quais foram lidos na íntegra, sumariados e ordenados, buscando obter respostas ao problema da pesquisa. Considerando o objetivo do estudo, 0 tema apresenta-se conforme mostra a Figura 1.

Figura 1: Representação da realização da busca dos artigos para a temática do estudo.

Busca dos estudos nas bases de dados PubMed.

Recorte idiomático, de repetição, incompletos (sem resumo) e dos últimos 10 anos.
Foram utilizados os descritores: "Linseed Oil" and "Diabetes mellitus, type 2" and "Diet, Food, and Nutrition".

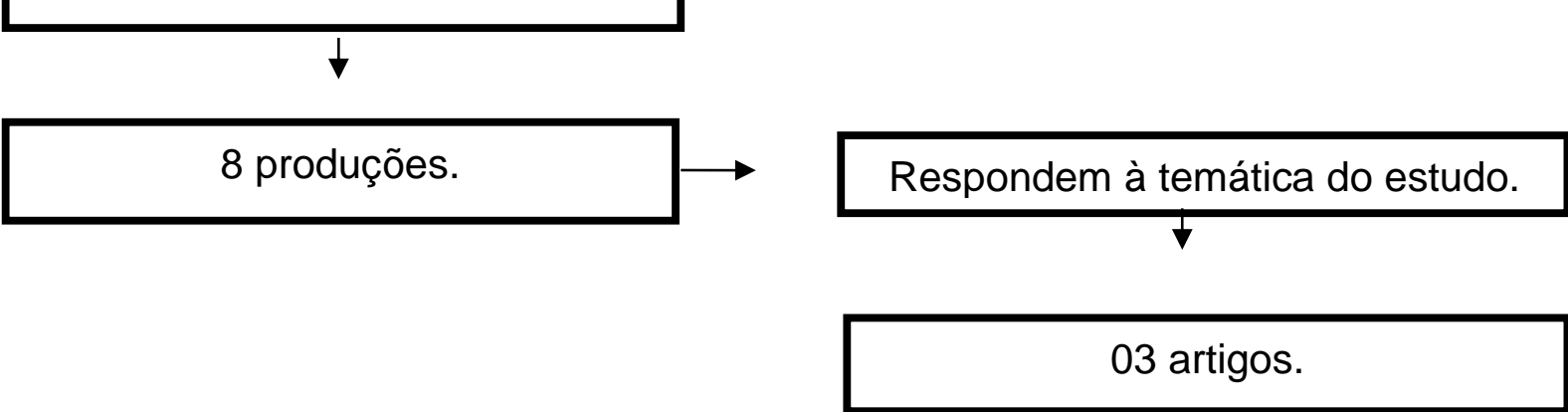

\section{RESULTADOS E DISCUSSÕES}

Neste estudo foram selecionados três artigos para as discussões, após aplicação do critério de inclusão e exclusão. Os artigos selecionados foram publicados entre os anos de 2016 a 2019 sendo que as publicações foram, respectivamente, por médicos, nutricionistas e bioquímicos.

Os estudos correlacionaram dados sociodemográficos e clínicos, 
parâmetros de homeostase da glicose, perfil lipídico e biomarcadores de inflamação dos participantes.

Após a busca, foi preenchido um instrumento contendo: título, objetivo, metodologia, principais resultados e conclusões dos estudos, conforme a mostra o Quadro 1.

QUADRO 1: Representação da realização da busca dos artigos para a temática do estudo.

\begin{tabular}{|c|}
\hline $\begin{array}{c}\text { Comparação entre os efeitos do óleo de linhaça e da suplementação com óleo de } \\
\text { peixe na saúde cardiovascular em pacientes diabéticos tipo } 2 \text { com doença cardíaca } \\
\text { coronária: um ensaio randomizado, duplo-cego e controlado por placebo } \\
\text { RAYGAN et al., } 2019\end{array}$ \\
\hline Objetivo \\
\hline $\begin{array}{l}\text { Comparou os efeitos da suplementação de linhaça e óleo de peixe nos parâmetros de risco } \\
\text { cardiovascular em pacientes diabéticos com doença cardíaca coronária. }\end{array}$ \\
\hline Método \\
\hline $\begin{array}{c}\text { Os participantes foram alocados aleatoriamente em três grupos de intervenção para receber } \\
1.000 \mathrm{mg} \text { de ácidos graxos ômega-3 de óleo de peixe ou } 1.000 \mathrm{mg} \text { de ácidos graxos ômega- } \\
3 \text { de óleo de linhaça ou placebo ( } \mathrm{n}=30 \text { cada grupo }) \text { duas vezes por dia durante } 12 \\
\text { semanas. }\end{array}$ \\
\hline Resultados \\
\hline $\begin{array}{c}\text { Uma redução nos níveis de insulina foi observada após a suplementação com óleo de } \\
\text { linhaça e óleo de peixe em comparação com o placebo. Além disso, uma redução na } \\
\text { proteína C reativa foi observada após a suplementação de óleo de linhaça em comparação } \\
\text { com o placebo e um aumento no nitrito total foi observado após a ingestão de óleo de } \\
\text { linhaça e óleo de peixe em comparação com placebo. Adicionalmente, foi observado um } \\
\text { aumento significativo na capacidade antioxidante total após consumir óleo de linhaça e óleo } \\
\text { de peixe em comparação com placebo e níveis de glutationa após consumir óleo de peixe } \\
\text { em comparação com óleo de linhaça e placebo. }\end{array}$ \\
\hline Conclusões \\
\hline $\begin{array}{l}\text { O estudo revelou os efeitos benéficos da suplementação com óleo de linhaça e óleo de } \\
\text { peixe por } 12 \text { semanas sobre os níveis de insulina sérica, nitrito total plasmático e capacidade } \\
\text { antioxidante total em pacientes diabéticos com doença cardíaca coronária. A ingestão de } \\
\text { óleo de linhaça reduziu significativamente os níveis de Proteína C reativa-ultrassensível em } \\
\text { comparação com o placebo. A ingestão de óleo de peixe aumentou os níveis plasmáticos de } \\
\text { glicose plasmática em jejum em comparação com o óleo de linhaça e o placebo. Este estudo } \\
\text { sugere que o efeito do óleo de linhaça na redução da secreção da insulina e no aumento do } \\
\text { nitrito total e da capacidade antioxidante total é semelhante ao do óleo de peixe. }\end{array}$ \\
\hline $\begin{array}{l}\text { Suplementação do óleo de linhaça melhora os níveis de expressão gênica de PPAR-y, } \\
\text { LP (a), IL-1 e TNF- } \alpha \text { em pacientes diabéticos tipo } 2 \text { com doença cardíaca coronária } \\
\text { HASHEMZADEH et al., } 2017\end{array}$ \\
\hline Objetivo \\
\hline $\begin{array}{l}\text { Determinar os efeitos da administração de óleo de linhaça nos níveis de expressão gênica } \\
\text { relacionados à insulina, lipídios e inflamação em pacientes diabéticos com sobrepeso e } \\
\text { doença cardíaca coronária. }\end{array}$ \\
\hline Método \\
\hline $\begin{array}{l}\text { Ensaio randomizado, duplo-cego e controlado por placebo foi conduzido entre } 60 \text { pacientes } \\
\text { diabéticos com doença renal crônica. Os indivíduos foram alocados aleatoriamente em dois } \\
\text { grupos para ingestão de } 1000 \mathrm{mg} \text { de ácido graxo } \mathrm{n}-3 \text { de óleo de linhaça contendo } 400 \mathrm{mg} \text { de } \\
\text { ácido a-linolênico ou placebo }(n=30) \text { duas vezes por dia durante } 12 \text { semanas. }\end{array}$ \\
\hline
\end{tabular}




\begin{tabular}{|c|}
\hline \\
\hline \\
\hline \multirow[t]{2}{*}{$\begin{array}{l}\text { A reação de transcriptase reversa seguida de reação em cadeia da polimerase (RT-PCR) } \\
\text { demonstrou que após a intervenção de } 12 \text { semanas, em comparação com o placebo, a } \\
\text { suplementação com óleo de linhaça pode aumentar a expressão gênica do receptor gama } \\
\text { ativado por proliferador de peroxissoma (PPAR-y) em células mononucleares do sangue } \\
\text { periférico de pacientes diabéticos com doença cardíaca coronária. Além disso, em } \\
\text { comparação com o placebo, ingerir suplementos com óleo de linhaça reduziu os níveis de } \\
\text { expressão gênica de lipoproteína, interleucina-1 (IL-1) e tumor fator de necrose alfa (TNF- } \alpha \text { ) } \\
\text { em células mononucleares do sangue periférico de pacientes diabéticos com doença } \\
\text { cardíaca coronária. Não observamos nenhum efeito significativo da suplementação com óleo } \\
\text { de linhaça nos níveis de expressão gênica do receptor de lipoproteína de baixa densidade } \\
\text { (LDLR), IL-8 e fator transformador de crescimento beta (TGF- } \beta \text { ) em células mononucleares } \\
\text { do sangue periférico de pacientes diabéticos com doença cardíaca coronária. } \\
\text { Conclusões }\end{array}$} \\
\hline \\
\hline $\begin{array}{l}\text { A suplementação com óleo de linhaça por } 12 \text { semanas em pacientes diabéticos com doença } \\
\text { cardíaca coronária melhorou significativamente os níveis de expressão gênica de receptor } \\
\text { ativado por proliferadores de peroxissoma gama, lipoproteína (a), IL-1 e TNF-a. }\end{array}$ \\
\hline $\begin{array}{c}\text { Suplementação com óleo de linhaça modula correlações entre os níveis séricos } \\
\text { individuais de ácidos graxos livres e resistência à insulina em diabéticos tipo } 2 \text {. A } \\
\text { resistência à insulina e o porcentual da função das células } \beta \text { pancreáticas restantes } \\
\text { não são afetadas } \\
\text { BARRE et al., } 2016\end{array}$ \\
\hline Objetivo \\
\hline $\begin{array}{l}\text { Testar a hipótese de que haveria relação (correlação) diferente entre os níveis individuais de } \\
\text { ácidos graxo livres em matéria microscópica livre no soro sanguíneo e HOMA-IR e / ou } \\
\text { HOMA-\% } \beta \text { em diabéticos mellitus tipo } 2 \text {. }\end{array}$ \\
\hline Método \\
\hline $\begin{array}{l}\text { Os pacientes foram recrutados por meio de um anúncio de jornal e dois médicos foram } \\
\text { contratados. Todos os pacientes compareceram um e três meses depois para uma segunda } \\
\text { visita. Na segunda visita, os indivíduos foram aleatoriamente designados (duplo-cego) para } \\
\text { tratamento com óleo de linhaça ou cártamo por três meses, até a terceira visita. }\end{array}$ \\
\hline Resultados \\
\hline $\begin{array}{l}\text { Foram encontradas diferentes correlações ou tendências estatisticamente significativas entre } \\
\text { alguns níveis séricos de ácidos graxo livres em matéria microscópica em HOMA-IR e HOMA- } \\
\% \beta \text {, pré e pós-linhaça e suplementação de óleo de cártamo. No entanto, o óleo de linhaça } \\
\text { não teve impacto no HOMA-IR ou HOMA- } \beta \text {, apesar das alterações estatisticamente } \\
\text { significativas nas correlações em comparação com o HOMA-IR basal. }\end{array}$ \\
\hline Conclusões \\
\hline \\
\hline
\end{tabular}

Considerando o padrão alimentar da população atual caracterizado pela abundante ingestão de gorduras e sendo este um fator de influência no desenvolvimento do DM II que é considerado um desafio para a saúde mundial e destaca-se atualmente, como umas das principais causas de mortalidade e morbidade (KONATÉ et al., 2014; SBD, 2020).

Diante dos fatos mencionados, muitas plantas são utilizadas para 0 tratamento do DM e seus compostos químicos ativos tem desempenhado um agente promissor para o bom controle da glicose trazendo diversos benefícios à 
saúde (PALOMBO, 2006).

A linhaça uma semente oleaginosa, possui diversos benefícios para a saúde como efeito antioxidante, hipoglicemiantes, auxilia na redução de dislipidemias e possui benefícios para controle e redução do desenvolvimento de DM II (PRASSAD, DHAR, 2016).

Diante disso e após análise dos respectivos resultados, em uma comparação entre os efeitos da suplementação de óleo de linhaça e óleo de peixe sobre parâmetros metabólicos de risco cardiovascular em pacientes com DM II com doença coronariana durante 12 semanas. Houve uma redução significativa nos níveis de insulina e aumento nos níveis de nitrito total e antioxidante total em ambos os grupos em relação ao placebo. Foi observado no grupo suplementado com óleo de linhaça em comparação com o placebo uma redução significativa na alta sensibilidade na PCR (RAYGAN et al., 2019).

Corroborando com o autor, em um estudo randomizado controlado com placebo, após a suplementação de ácidos omega-3 de óleo de linhaça na dosagem de $1.000 \mathrm{mg}$ / dia por 12 semanas diminuiu significativamente os níveis de insulina, triglicerídeos e colesterol VLDL no soro, enquanto aumentou a sensibilidade à insulina em pacientes (SOLEIMANI et al., 2017).

Em um outro estudo de Soleimani et al., 2017, durante a suplementação de ácidos graxos ômega-3 com óleo de linhaça na dosagem de 2 g / dia por 12 semanas em pacientes com lesão ulcerativa nos membros inferiores diabéticos tipo II em comparação ao placebo diminuiu significativamente a PCRultrassensível, enquanto aumentou a capacidade antioxidante total e glutationa total plasmática.

Contudo, existem estudos divergentes na literatura, em um estudo a suplementação de óleo de linhaça em alta dose $(60 \mathrm{mg}$ de ALA/kg de peso corporal/dia) durante três meses por 40 participantes não teve efeito significativo sobre HOMA-IR e / ou HOMA- $\beta$ em pacientes com DM II em comparação com o basal em diabéticos tipo II. Esses resultados inconclusivos podem estar relacionados a alta dose de suplementação das formulações utilizadas ou possivelmente à duração do estudo (BARRE et al., 2016). 


\section{EDUCAÇÃO, SAÚDE \\ ETECNOLOGIA}

26 A 28 DE OUTUBRO DE 2021

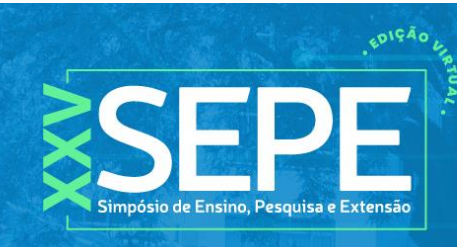

Diante disso, o aumento da resistência à insulina e hiperinsulinemia em pacientes com diabetes e doença coronariana aumenta significativamente a taxa de mortalidade, o risco de doenças macrovasculares, como doença arterial coronariana, doença arterial periférica e acidente vascular cerebral (VARUGHESE, TOMSON, LIP, 2005).

Em um estudo de coorte prospectiva após avaliação do consumo alimentar de uma população chinesa foi concluído que o consumo de fontes não marinhas de ácidos graxos ômega-3 está associado a uma diminuição no risco de desenvolvimento de DM II (BROSTOW et al., 2011).

Hashemzadeh et al. (2017) após realizar uma intervenção de 12 semanas com suplementação com óleo de linhaça aumentou a expressão gênica do receptor gama ativado por proliferador de peroxissoma em células mononucleares do sangue periférico de pacientes diabéticos com doença cardíaca coronariana.

No geral, a suplementação de óleo de linhaça em pacientes diabéticos com doença cardíaca coronariana melhorou significativamente os níveis de expressão gênica de proliferador de peroxissoma, níveis de expressão gênica de lipoproteína, interleucina 1 e fator de necrose tumoral-alfa (HASHEMZADEH et al., 2017).

Um estudou que ratifica com tais dados demostrou que uma dieta rica em carboidratos estimula o estresse oxidativo e modificações inflamatórias, tais como elevação dos níveis de TNF - alfa e IL-6 associados a intolerância a glicose o que provocam a inflamação subclínica (DANDONA, ALJADA, BANDYOPADHYAY, 2004; KASSIM-KARAKAS et al., 2006).

\section{CONCLUSÃO}

A partir dos respectivos estudos, pode-se concluir que a linhaça é considerada um alimento funcional e possui efeito benéfico para os portadores de DM II, auxiliando significativamente nos níveis de insulina sérica, aumentando os níveis de expressão gênica de receptor ativado por proliferadores de peroxissoma gama, diminuindo a lipoproteína (a), IL-1, TNF-a e PCRultrassensível. 
No entanto, é necessário a realização de novos estudos relacionados a temática referente as recomendações de consumo, visto que este é um questionamento a ser esclarecido para oferecer maior suporte no uso desta semente como um potencial agente alimentar para auxílio no controle glicêmico.

Diante do contexto o consumo de óleo de linhaça serve como um aliado para o controle glicêmico e perfil lipídico, juntamente, associado a mudança no estilo de vida e dentro de uma alimentação saudável e equilibrada.

\section{REFERÊNCIAS}

ALMEIDA, K. C. L. de et al. A linhaça (Linum usitatissimum) como fonte de ácido a-linolênico na formação da bainha de mielina. Revista de Nutrição, Campinas, 2009. DOI: 10.1590/S1415-52732009000500015

ALVES, M. R et al. Avaliação Do Consumo De Alimentos Funcionais Em Portadores De Síndrome Metabólica. Revista Redes de Cuidado em Saúde. Rio de Janeiro Vol. 9, № 1, 2015. Disponível em: http://publicacoes.unigranrio.edu.br/index.php/rcs/article/view/2508

BASHO, S. M., BIN, M. C. Propriedades dos alimentos funcionais e seu papel na prevenção e controle da hipertensão e diabetes. Interbio, v. 4, n. 1, p. 4858, 2010. ISSN 1981-3775

BARRE, D. E. et al. Flaxseed oil supplementation manipulates correlations between serum individual mol \% free fatty acid levels and insulin resistance in type 2 diabetics. Insulin resistance and percent remaining pancreatic $\beta$-cell function are unaffected. Endocrine Regulations. 2016. DOI: 10.1515/enr2016-0020.

BARKER, David James Purslove et al. Type 2 (non-insulin-dependent) diabetes mellitus, hypertension and hyperlipidaemia (syndrome $\mathrm{X}$ ): relation to reduced fetal growth. Diabetologia, 1993. DOI: 10.1007/BF00399095 
BARROS, Luciana Paes de et al. Avaliação da qualidade de vida em adolescentes: revisão da literatura. Jornal brasileiro de psiquiatria, Rio de Janeiro, v. 57, n. 3, p. 212-217, $2008 . \quad$ Disponível em: http://www.scielo.br/scielo.php?script=sci arttext\&pid=S004720852008000300009\&lng=en\&nrm=iso.

BROSTOW, D. P. et al. Omega-3 fatty acids and incident type 2 diabetes: the Singapore Chinese The American Journal of Clinical Nutrition, 2011. DOI: 10.3945 / ajcn.110.009357

DANDONA, P.; ALJADA, A., BANDYOPADHYAY, A. Inflamação: a ligação entre a resistência à insulina, obesidade e diabetes. Trends in immunology, 2004. DOI: $\underline{10.1016 / j . i t .2003 .10 .013}$

FONSECA, H.; GUTIERREZ, L. Composição em ácidos graxos de óleos vegetais e gorduras animais. Anais Da Escola Superior De Agricultura Luiz De Queiro, v. 31, 1974. DOI: 10.1590/S0071-12761974000100038.

HASHEMZADEH, A. A et al., Flaxseed Oil Supplementation Improve Gene Expression Levels of PPAR-y, LP(a), IL-1 and TNF- $\alpha$ in Type 2 Diabetic Patients with Coronary Heart Disease. Lipids, 2017. DOI: 10.1007/s11745-0174295-5.

INTERNATIONAL DIABETES FEDERATION. International Diabetes Federation. IDF Atlas. 8. ed. Bruxelas, 2017. Disponível em: https://www.idf.org/e-library/epidemiology-research/diabetes-atlas/134-idfdiabetes-atlas-8th-edition.html.

KASSIM-KARAKAS, S. E et al. Responses of inflammatory markers to a low-fat, high-carbohydrate diet: effects of energy intake. Controlled Clinical Trial, 2006. DOI: 10.1093/ajcn/83.4.774

KONATÉ K. et al. Free Radicals Scavenging Capacity, Antidiabetic and Antihypertensive Activities of Flavonoid-Rich Fractions from Leaves of Trichilia emetica and Opilia amentacea in an Animal Model of Type 2 Diabetes Mellitus. 
Evidence- Based Complementary and Alternative Medicine, 2014. DOI: https://doi.org/10.1155/2014/867075

LOTTENBERG, A. M. P. Características da dieta nas diferentes fases da evolução do diabetes melito tipo 1. Arquivos Brasileiros de Endocrinologia Metabólica, São Paulo, v. 52, 2008. DOI:10.1590/S0004-27302008000200012

PALOMBO, E. A. Phytochemicals from traditional medicinal plants used in the treatment of diarrhoea: modes of action and effects on intestinal function.

Phytotherapy Research, 2006. DOI: 10.1002/ptr.1907

PRASAD, K; DHAR, A. Flaxseed and Diabetes. Current Pharmaceutical Design 2016;22(2):141-4. Disponível em: DOI: $10.2174 / 1381612822666151112151230$

RAYGAN, F. et al., A comparison between the effects of flaxseed oil and fish oil supplementation on cardiovascular health in type 2 diabetic patients with coronary heart disease: A randomized, double-blinded, placebo-controlled trial. Phytother Research. 2019 DOI: 10.1002/ptr.6393. Epub 2019 Jun 13.

SBD. Diretrizes da Sociedade Brasileira de Diabetes 2019-2020. Disponível em: https://www.diabetes.org.br/profissionais/images/DIRETRIZESCOMPLETA-2019-2020.pdf

SOLEIMANI, Z. et al. Metabolic response to omega-3 fatty acid supplementation in patients with diabetic nephropathy: A randomized, doubleblind, placebo-controlled trial. Clinical Nutrion. 2017. DOI: 10.1016/j.Clnu.2015.11.003.

SOLEIMANI, Z. et al. Clinical and metabolic response to flaxseed oil omega-3 fatty acids supplementation in patients with diabetic foot ulcer: A randomized, double-blind, placebo-controlled trial. Journal of Diabetes and its

Complications, 2017. DOI:10.1016/.j.jdiacomp.2017.06.010 


\section{ETECNOLOGA}

VARUGHESE, G. I, TOMPSON, J., LIP, G. Y. Type 2 diabetes mellitus: a cardiovascular perspective. International Journal Clinical Practic. 2005. DOI: 10.1111/j.1368-5031.2005.00571.x. PMID: 15963208. 